\title{
Synthesis and characterization of novel polyester containing Schiff-base unit
}

\author{
Hossein Mighani ${ }^{1 *}$, Ehsan Fathollahi' and Moosa Ghaemy² \\ ${ }^{1}$ Laboratory of Polymer Chemistry, Department of Chemistry, Faculty of Science, \\ Golestan University, Gorgan, Iran \\ ${ }^{2}$ Faculty of Chemistry, Mazandaran University, Babolsar, Iran \\ *h.mighani@gu.ac.ir
}

\begin{abstract}
A new Schiff base type of polyester containing 2,2-dimethyl-1,3-diaminopropane was prepared by solution polycondensation of 1,4-benzenedicarbonyl dichloride with $\mathrm{Bis}$ (4-hydroxybenzilaldehid)-2,2-dimethyl-1,3-propildiimine $\left(\mathrm{H}_{2} \mathrm{HB}_{2} \mathrm{P}\right)$ which is derived from a 2,2-dimethyl-1,3-diaminopropane Schiff base reacted with a 4-hydroxybenzaldehyde monomer. The monomer and the polyester were characterized by FTIR, ${ }^{1} \mathrm{HNMR}$, and elemental analysis. The prepared polyester showed inherent viscosity of $0.29 \mathrm{dl} / \mathrm{g}$ in $\mathrm{NMP}$ at $25^{\circ} \mathrm{C}$, indicating their moderate molecular weight. The Polyester was completely soluble in aprotic polar solvents such as $N$-methylpyrolidone (NMP), dimethylformamide (DMF), Dimethyl Acetamid (DMAC), dimthylsulfoxide (DMSO). TGA determined the $10 \%$ weight loss temperature $\left(\mathrm{T}_{10}\right)$ at $280{ }^{\circ} \mathrm{C}$ and residual weight at $600{ }^{\circ} \mathrm{C}$ ca. $41 \%$ under nitrogen atmosphere.
\end{abstract}

Keywords: polyester, Schiff base, 2, 2-dimethyl-1, 3-diaminopropane, thermal stability.

\section{Introduction}

Polymers have received significant attention due to their lightness and favorable physical and chemical properties. Amongst polymers, polyesters have been the subject of numerous commercial applications. This in turn, has attracted a plethora of researches and studies in the synthesis of polyesters from diols and diacid chlorides by condensation polymerizations ${ }^{[1,2]}$. Synthesis of polymers with conjugative bonds including $-\mathrm{C}=\mathrm{N}-$ and $-\mathrm{C}=\mathrm{C}-$ in the main chain has grabbed researcher's interests for many years ${ }^{[3-8]}$. Generally, Schiff base bonds confers appropriate features such as; thermal stability, conductivity, liquid crystal properties and chelating effects to polymers ${ }^{[9,10]}$. Nowadays, polyesters with Schiff base units have been an interesting area for researchers due to the particular properties. Aromatic structures in this class of polymers have a high thermal stability ${ }^{[1]}$. Aromatic polymers with Schiff base units have a high thermal stability, they suffer from low solubility. To solve this problem, many efforts were triggered toward increasing the solubility ${ }^{[12,13]}$. Substituting flexible groups along the main chain of polyesters with Schiff base units is of strategies to enhance the solubility in organic solvents ${ }^{[14]}$. In this paper for the first time we investigate the synthesis and characterization of polyester containing Schiff base unit with high solubility by solution polymerization of bis(4-hydroxybenzaldehyde)- 2,2 dimethyl-1,3-propyl $\operatorname{diamin}\left(\mathrm{H}_{2} \mathrm{HB}_{2} \mathrm{P}\right)$ with terephthaloyl dichloride. Monomer and resultant polymer was characterized by FT-IR, ${ }^{1} \mathrm{HNMR}$ and CHNS. Also the inherent viscosity, solubility and thermal stability of the polymer were studied.

\section{Experimental}

\subsection{Materials and instruments}

2, 2-dimethyl-1, 3-diaminopropane, 4-hydroxybenzaldehyde, terephthaloyl dichloride and solvents were purchased from Fluka and used without further purification. ${ }^{1} \mathrm{HNMR}$ spectra were recorded on a $500 \mathrm{MHz}$ Bruker Advance DRX instrument using DMSO-d6 as solvent and tetramethylsilane as an internal standard. FT-IR spectra were recorded using a Bruker Vector 22 spectrometer on $\mathrm{KBr}$ pellets. The CHN-600 Leco analyzer was used for elemental analysis. Thermal gravimetric analysis (TGA) and differential scanning calorimetery (DSC) were performed using Perkin-Elmer Pyris and MetlerTolledo 822e, respectively. Inherent viscosity $\left([\eta]_{\text {inh }}=\ln \eta_{\text {rel }} / \mathrm{c}\right.$, at a concentration of $\left.0.5 \mathrm{~g} / \mathrm{dl}\right)$ was measured with an Ubbelhode suspended-level viscometer at $25^{\circ} \mathrm{C}$ in NMP solution.

\subsection{Pre-treatment of monomer}

In a $250 \mathrm{~mL}$ round bottom flask equipped with a magnetic stirring, 4-hydroxybenzaldehyde (3.15 g, $26 \mathrm{mmol})$ dissolved in a mixture of $40 \mathrm{~mL}$ methanol, $1 \mathrm{~mL}$ of conc. $\mathrm{HCl}$ was added. A solution of 2, 2-dimethyl-1, 3-diaminopropane (1.32 g, $13 \mathrm{mmol}$ ) in $30 \mathrm{~mL}$ of methanol and few drops were added to the flask. The mixture was stirred for $5 \mathrm{~h}$ under reflux condition. After cooling the reaction, The precipitated product, Bis (4-hydroxybenzilaldehid)-2, 2-dimethyl-1,3-propildiimine $\left(\mathrm{H}_{2} \mathrm{HB}_{2} \mathrm{P}\right)$ (Scheme 1), was collected by filtration, washed with ethanol and dried in a vacuum oven at $70{ }^{\circ} \mathrm{C}$ for $3 \mathrm{~h}$. A yellow product was obtained in $65 \%$ yield with a melting point of $186^{\circ} \mathrm{C}$. IR $(\mathrm{KBr})\left(\delta_{\max } \mathrm{cm}^{-1}\right): 3205(\mathrm{OH}), 1649(\mathrm{CN}), 1585\left(\mathrm{C}=\mathrm{C}_{\mathrm{Ar}}\right)$. ${ }^{1} \mathrm{HNMR}\left(400, \mathrm{DMSO}, \mathrm{d}_{6}, \mathrm{TMS}\right) \delta \mathrm{ppm}: 9.86(1 \mathrm{H}, \mathrm{S}, \mathrm{OH})$, 


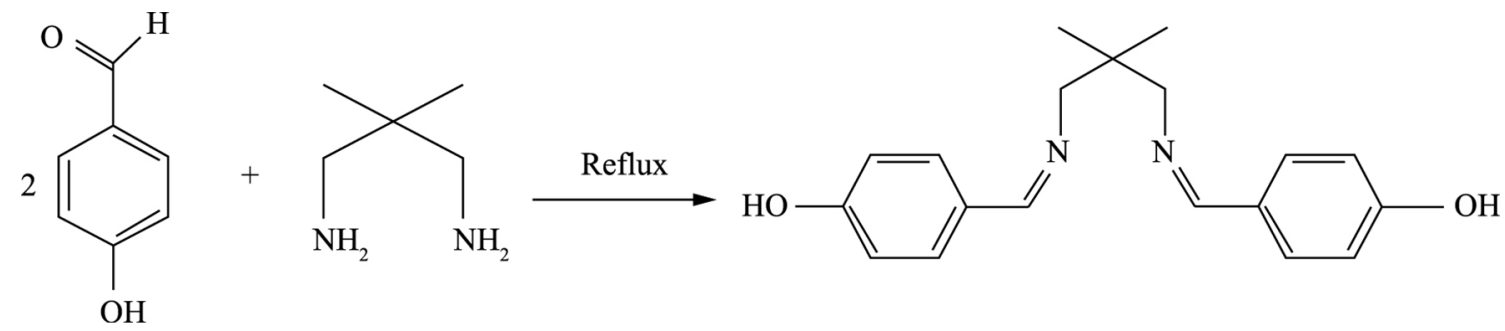

Scheme 1. Synthesis of $\mathrm{H}_{2} \mathrm{HB}_{2} \mathrm{P}$.

$8.16(1 \mathrm{H}, \mathrm{S}, \mathrm{NH}), 0.93-1.04\left(6 \mathrm{H}, \mathrm{t}, \mathrm{CH}_{\text {methyl }}\right), 3.42-3.56$ (4H, C, $\left.\mathrm{CH}_{\text {methylene }}\right)$.

\subsection{Preparation of polyester}

In a two-necked flask $100 \mathrm{~mL}$ equipped with a dropping funnel and gas inlet tube was charged with a mixture of Bis(4-hydroxybenzilaldehid)-2,2-dimethyl-1,3-propildiimine (0.62 g, $2 \mathrm{mmol}$ ), $20 \mathrm{~mL}$ dimethylformamide (DMF) and triethylamine $(0.8 \mathrm{~mL}) .1$, 4-benzenedicarbonyl dichloride (0.40 g, $2 \mathrm{mmol})$ dissolved in $10 \mathrm{~mL}$ DMF was added drop wise to the stirred solution at $0{ }^{\circ} \mathrm{C}$ under $\mathrm{N}_{2}$ atmosphere. The mixture was subsequently stirred at ambient temperature for $5 \mathrm{~h}$ under $\mathrm{N}_{2}$ and then it was poured into cold water. The yellow solid product was separated by filtration and washed with $\mathrm{NaHCO}_{3}$ solution. Then polymer washed with methanol, and dried under reduced pressure at $80^{\circ} \mathrm{C}$ for $24 \mathrm{~h}$.Yield $60 \%$, IR $(\mathrm{KBr})\left(\delta_{\max } \mathrm{cm}^{-1}\right): 1736(\mathrm{C}=\mathrm{O})$, 1210 and $1270(\mathrm{C}-\mathrm{O}), 1598(\mathrm{C}=\mathrm{C}), 1660(\mathrm{C}=\mathrm{N}) .{ }^{1} \mathrm{HNMR}$ (400, DMSO, d 6 , TMS) $\delta$ ppm: 0.93-1.06 $\left(6 \mathrm{H}, \mathrm{CH}_{\text {methyl }}\right)$, 3.36-3.52 (4H, $\left.\mathrm{CH}_{\text {methylene }}\right), 7.40-8.39\left(12 \mathrm{H}, \mathrm{CH}_{\mathrm{Ar}}\right), 8.40$ $(2 \mathrm{H}, \mathrm{CH}=\mathrm{N})$. Anal.Cald. for $\left[\mathrm{C}_{27} \mathrm{H}_{24} \mathrm{~N}_{2} \mathrm{O}_{4}\right]: \mathrm{C}, 73.64 ; \mathrm{H}$, $5.45 ; \mathrm{N}, 6.36$. Found: C, 74.54; H, 5.22; N, 7.06.

\section{Result and Discussion}

Scheme 1 depicts route for synthesis of monomer $\left(\mathrm{H}_{2} \mathrm{HB}_{2} \mathrm{P}\right)$. The band at $3205 \mathrm{~cm}^{-1}$ is associated to $\mathrm{OH}$, while the band at $1649 \mathrm{~cm}^{-1}$ can be attributed to the imine group $(\mathrm{N}=\mathrm{C})$. The absorption peak at $1585 \mathrm{~cm}^{-1}$ is characteristic of double bond group $(\mathrm{C}=\mathrm{C})$. The Figure $1,{ }^{1} \mathrm{HNMR}$ spectra showed the $\mathrm{OH}$ protons in $9.86 \mathrm{ppm}$, the peak at around $8.16 \mathrm{ppm}$ is assigned to $\mathrm{NH}$, and methyl peak is observed in $1.04-0.93 \mathrm{ppm}$ and the peak from 3.42-3.47 ppm is characteristic of methylene. Polyester is synthesized by polymerization of $\mathrm{H}_{2} \mathrm{HB}_{2} \mathrm{P}$ with terephthaloyl dichloride in the presence of triethylamine. Reaction was carried out in DMF as $\mathrm{H}_{2} \mathrm{HB}_{2} \mathrm{P}$ solvent and terephthaloyl dichloride in nitrogen atmosphere at room temperature. The result of elemental analysis is closely similar to calculated percentages. Elemental percentages are obtained as follows: C, 74.54\% (73.64\% calculated); H, $5.22 \%(5.45 \%)$; N, 7.06\% (6.36\%). Polyester was also characterized with ${ }^{1} \mathrm{HNMR}$ and IR Spectroscopy. In Figure 2, showed IR spectra peaks; the peak at $1736 \mathrm{~cm}^{-1}$ is associated to (stretch $\mathrm{C}=\mathrm{O}$ ), and the peak at $1660 \mathrm{~cm}^{-1}$ is characteristic of $(\mathrm{N}=\mathrm{C})$ and the peak at $1598 \mathrm{~cm}^{-1}$ is related to (stretch $\left.\mathrm{C}=\mathrm{C}\right)$. ${ }^{1} \mathrm{HNMR}$ spectra of the representative polyester, in Figure 3, showed signals at $8.40 \mathrm{ppm}$ due to the proton of azomethine, at 7.40-8.39 ppm related to the protons of aromatic groups, the protons of methyl at $0.93-1.06 \mathrm{ppm}$ and in the regions

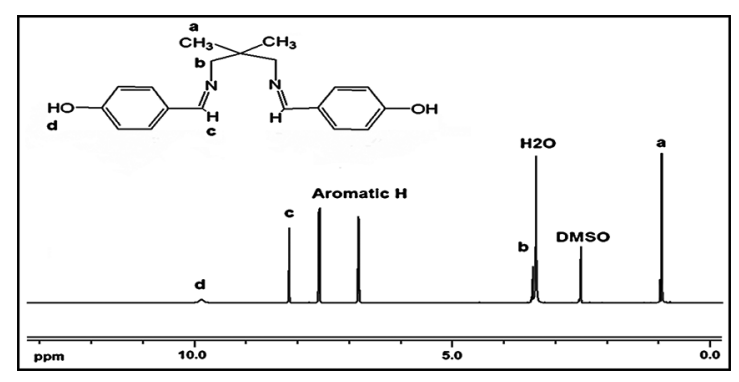

Figure 1. ${ }^{1} \mathrm{HNMR}$ of $\mathrm{H}_{2} \mathrm{HB}_{2} \mathrm{P}$.

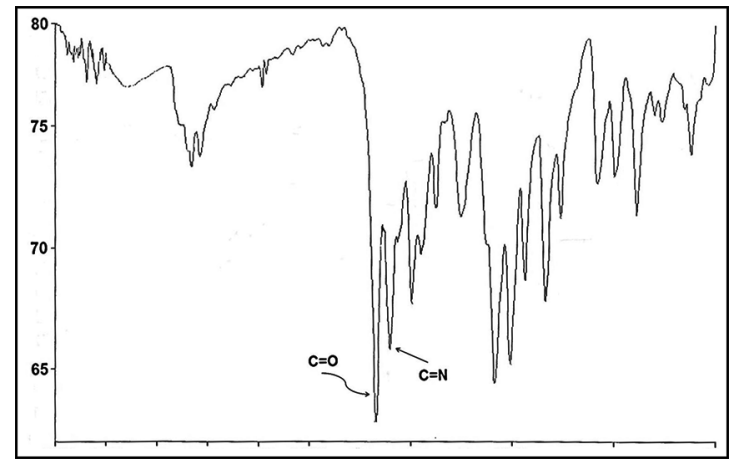

Figure 2. IR of polyester.

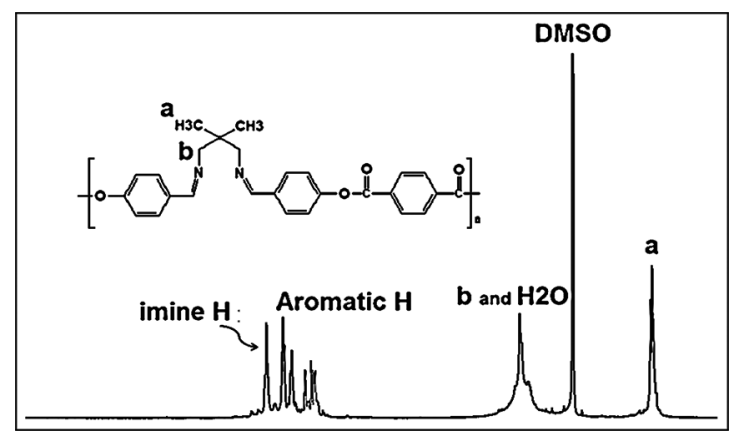

Figure 3. ${ }^{1} \mathrm{HNMR}$ of polyester.

of 3.36-3.52 ppm corresponding to aromatic protons and water proton. The inherent viscosity [ $\eta]$ of polymer was measured in NMP, equal to $0.29 \mathrm{dl} / \mathrm{g}$. It is well established that viscosity has direct relation with molecular weight therefore polyester possess a reasonable molecular weight. Polyester was dissolved easily in NMP, DMF, DMAC and 
Table 1. The physical and thermal properties of polyester.

\begin{tabular}{|c|c|c|c|c|c|}
\hline Yield (\%) & $\eta^{\mathrm{a}}{ }_{\mathrm{inh}}(\mathrm{dl} / \mathrm{g})$ & $\mathrm{T}_{\mathrm{g}}^{\mathrm{b}}\left({ }^{\circ} \mathrm{C}\right)$ & $\mathrm{T}_{10 \%}{ }^{\mathrm{c}}\left({ }^{\circ} \mathrm{C}\right)$ & $\mathbf{T}_{20 \%}{ }^{\mathrm{d}}\left({ }^{\circ} \mathrm{C}\right)$ & $\mathbf{R}_{w}(\%)^{c}$ \\
\hline 60 & 0.29 & 174 & 268 & 341 & 41.4 \\
\hline
\end{tabular}

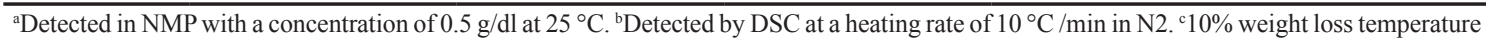
(Determined by TGA at a scan rate of $10{ }^{\circ} \mathrm{C} / \mathrm{min}$ in N2). ${ }^{\mathrm{d}} 20 \%$ weight loss temperature (Determined by TGA at a scan rate of $10{ }^{\circ} \mathrm{C} / \mathrm{min}$ in N2). ${ }^{\mathrm{e}}$ Residual weight (\%) when heated to $600{ }^{\circ} \mathrm{C}$ (Determined by TGA at a scan rate of $10{ }^{\circ} \mathrm{C} / \mathrm{min}$ in $\mathrm{N} 2$ ).

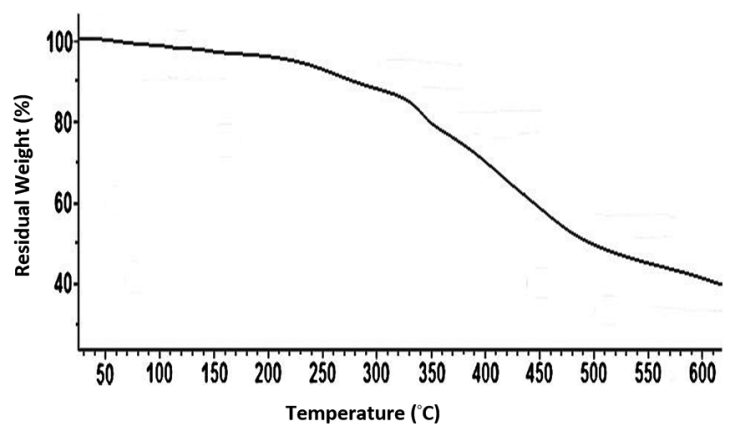

Figure 4. TGA of polyester.

DMSO at room temperature. It is hypothesized that this is because aliphatic structure of $\mathrm{H}_{2} \mathrm{HB}_{2} \mathrm{P}$ monomer enhance the flexibility of polymer. The polyester was insoluble in acetone and methanol. Thermal stability of polyester was investigated with TGA and DSC instruments. Differential scanning calorimeter (DSC) analysis was performed at a heating rate of $10^{\circ} \mathrm{C} / \mathrm{min}$. The scanning of polymer was carried out over $300{ }^{\circ} \mathrm{C}$. The glass transition temperature was recorded about $170{ }^{\circ} \mathrm{C}$. As anticipated, the $\mathrm{T}_{\mathrm{g}}$ value of this polyester depended on the structure of the diol aliphatic part employed. Thermal stability was carried out in nitrogen atmosphere. Polymer showed 10 percent weight loss over $270{ }^{\circ} \mathrm{C}$ and 50 percent weight loss over $400{ }^{\circ} \mathrm{C} .41 .4 \%$ of the polymer remained unchanged around $600^{\circ} \mathrm{C}$ (Figure 4). Physical and thermal properties were shown in Table 1.

\section{Conclusion}

Polyester was prepared from $\mathrm{H}_{2} \mathrm{HB}_{2} \mathrm{P}$ diol and terephthaloyl dichloride. With molar ratio of diol to diacid chloride 2:2 the polymerization was performed at room temperature under $\mathrm{N}_{2}$ atmosphere within 5 hours. Polyester was prepared, characterized and its thermal stability was investigated. The presence of aliphatic group increased the flexibility of diol and as a result enhanced the solubility of polyester. The poyester has a 10 percent weight loss at 268 and $20 \%$ weight loss at $341{ }^{\circ} \mathrm{C}$ and a residual weight (41.4\%) at $600^{\circ} \mathrm{C}$. The polyester has a glass transition temperature at $174{ }^{\circ} \mathrm{C}$ and it showed that the polyester is a thermally stable material. The inherent viscosity of polyester is $0.29 \mathrm{dl} / \mathrm{g}$ and showed a high molecular weight for polymer.

\section{Acknowledgements}

We acknowledge Golestan University (GU) for partial support of this work and mazandaran University (UMZ) for NMR spectral analysis.

\section{References}

1. Kricheldorf, H. R., Struve, O., \& Schwarz, G. (1996). Whiskers: 13. Polyesters based on 4, 4'-biphenyldiol and biphenyl- 4, 4'-dicarboxylic acid. Polymer, 37(19), 4311-4320. http://dx.doi. org/10.1016/0032-3861(96)00260-1.

2. Ludwig, H. (1971). Polyester fibers, chemistry and technology. New York: John Wiley.

3. Yang, J., Sun, W. L., Jiang, H. J., \& Shen, Z. Q. (2005). Synthesis and properties of two novel poly (Schiff base)s and their rare-earth complexes. Polymer, 46(23), 10478-10483. http://dx.doi.org/10.1016/j.polymer.2005.08.037.

4. Catanescu, O., Grigoras, M., Colotin, G., Dobreanu, A., Hurduc, N., \& Simionescu, C. I. (2001). Synthesis and characterization of some aliphatic-aromatic poly(Schiff base)s. European Polymer Journal, 37(11), 2213-2216. http://dx.doi.org/10.1016/ S0014-3057(01)00119-7.

5. Grigoras, M., Catanescu, C. O., \& Colotin, G. (2001). Poly(Schiff base)s containing 1,1'-binaphthyl moieties: synthesis and characterization. Macromolecular Chemistry and Physics, 202(11), 2262-2266. http://dx.doi.org/10.1002/15213935(20010701)202:11<2262::AID-MACP2262>3.0.CO;2-7.

6. Shi, S. Y., Li, Z., \& Wang, J. (2007). Synthesis and characterization of some novel conjugated polyoxadiazoles with Schiff base structure. Journal of Polymer Research, 14(4), 305-312. http:// dx.doi.org/10.1007/s10965-007-9111-0.

7. Khuhawar, M. Y., Mughal, M. A., \& Channar, A. H. (2004). Synthesis and characterization of some new Schiff base polymers. European Polymer Journal, 40(4), 805-809. http:// dx.doi.org/10.1016/j.eurpolymj.2003.11.020.

8. Youming, Z., Xinrong, D., Liangcheng, W., \& Taibao, W. (2008). Synthesis and characterization of inclusion complexes of aliphatic-aromatic poly(Schiff base)s with $\beta$-cyclodextrin (highlight). Journal of Inclusion Phenomena and Macrocyclic Chemistry, 60(3-4), 313-319. http://dx.doi.org/10.1007/s10847007-9379-z.

9. Coskun, Y., Cirpan, A., \& Toppare, L. (2004). Conducting polymers of terepthalic acid bis-(2-thiophen-3-yl-ethyl) ester and their electrochromic properties. Polymer, 45(15), 49894995. http://dx.doi.org/10.1016/j.polymer.2004.05.038.

10. Li, X. G., Zhou, H. J., \& Huang, M. R. (2005). Synthesis and properties of a functional copolymer from $N$-ethylaniline and aniline by an emulsion polymerization. Polymer, 46(5), 1523-1533. http://dx.doi.org/10.1016/j.polymer.2004.12.021.

11. Deng, F., He, W., Luyt, A. S., \& Jiang, Y. Y. (2011). Synthesis and properties of a novel polyester containing bithiazole. Chinese Chemical Letters, 22(1), 109-113. http://dx.doi.org/10.1016/j. cclet.2010.09.019.

12. Nepal, D. S., Samal, S., \& Geckeler, K. E. (2003). The first fullerene-terminated soluble poly(azomethine) rotaxane. Macromolecules, 36(11), 3800-3802. http://dx.doi.org/10.1021/ ma0258410.

13. Thomas, O., Inganäs, O., \& Andersson, M. R. (1998). Synthesis and properties of a soluble conjugated poly(azomethine) with high molecular weight. Macromolecules, 31(8), 2676-2678. http://dx.doi.org/10.1021/ma9701090. 
14. Kausar, A., \& Hussain, S. T. (2012). Processing and properties of new heteroaromatic Schiff-base poly(sulfone-ester)s and their blends. Iranian Polymer Journal, 22(3), 175-185. http:// dx.doi.org/10.1007/s13726-012-0116-0.

Received: Aug. 31, 2014

Revised: Jan. 18, 2015

Accepted: Feb. 26, 2015 